\title{
Moment or Movement - An Empirical Analysis of the Heterogeneous Impact of Media Attention on Charitable Crowdfunding Campaigns
}

\author{
Janina Seutter \\ Paderborn University \\ Janina.Seutter@, \\ upb.de
}

\author{
Michelle Müller \\ Paderborn University \\ Michelle.Mueller@, \\ upb.de
}

\author{
Stefanie Müller \\ Paderborn University \\ Stefanie.Mueller@, \\ upb.de
}

\author{
Dennis Kundisch \\ Paderborn University \\ Dennis.Kundisch@, \\ upb.de
}

\begin{abstract}
For issues receiving heightened media attention (e.g., natural disasters or social movements), charitable crowdfunding platforms offer an opportunity to generate donations. However, since media attention is typically short-lived, little is known about the long-term impact of temporary attention spikes on donation behavior for different types of crowdfunding campaigns. To address this gap, we examine how the Black Lives Matter movement and the associated social protest cycle after the death of George Floyd have influenced fundraising behavior for campaigns supporting the black community. By applying a differences-indifferences approach on a GoFundMe dataset, we find that campaigns with a personal funding goal only see an increase in donations for about three months, compared with over ten months for campaigns with a societal funding goal. If charitable crowdfunding platforms aim to help personal concerns, they need to signpost donors to such campaigns well beyond the temporal spike in the associated media attention.
\end{abstract}

\section{Introduction}

Donation-based crowdfunding platforms such as GoFundMe allow to set up campaigns in a matter of seconds and thus raise funds easily and without bureaucracy. GoFundMe, a U.S. (for-profit) company that brokers donations through an Internet platform, hosts a wide range of appeals for causes ranging from environmental and societal issues, to individual problems [1].

In recent years, donation campaigns on crowdfunding platforms have also started to spring up on controversial issues and social movements that have made the headlines. This reflects the growing awareness of social inequalities and discrimination, which disproportionately affects underrepresented groups, such as the black community or women, and has triggered a rethinking of attitudes in society. These social movements are often national or even global (e.g., \#BlackLivesMatter), and while they are usually of a long-term nature, there are also social protest cycles characterized by short periods of intense protest activity, which revive awareness of the movement and its importance to society, often triggered by events [2]. Generally speaking, media attention plays an important role for fundraising campaigns, influencing donor behavior and thus the likelihood of successful fundraising [3]. While a surge in donations to causes related to social movements or to controversial issues is nothing unusual, what is striking about them is that media interest around the world rises and falls just as quickly [2]. It remains unclear, however, how long such increases in donations last, or what types of fundraising campaigns actually benefit in its wake. Charitable crowdfunding platforms such as GoFundMe are known in particular for enabling private individuals to raise funds for personal matters. In practice, however, it can be observed that societal concerns are also cited as the underlying concern of some campaigns. As both campaigns with personal and with societal concerns can be launched on crowdfunding platforms, and a distinction between such campaigns is not directly possible, it remains unclear whether both types are equally affected by increases in donations triggered by social movements or similar protest actions that are in the spotlight of media.

Given the popularity of charitable crowdfunding platforms and the evolution of fundraising in the context of socially controversial issues profiled in the media, our research aims to shed light on the heterogeneous effects of media attention on social movements, and of underlying social protest cycles on donations in charitable crowdfunding markets. Research on such platforms will help reveal donation patterns for campaigns linked to social movements highlighted in the media, aiming to make developments in donation behaviors more transparent and measurable. Hence, we formulate two research questions:

RQ1: How does media attention for a social movement affect the donation behavior for crowdfunding campaigns related to that movement?

RQ2: Are there any systematic differences in the donation behavior for crowdfunding campaigns with a personal concern compared to those with a societal concern? 
The death of George Floyd on May 25 2020 sparked a wave of protests worldwide and triggered a social protest cycle for the Black Lives Matter (BLM) movement. This movement also reached GoFundMe, inspiring a number of campaigns, including its most successful fundraising campaign ever, the "Official George Floyd Memorial Fund", with donations reaching nearly \$15 million within one week [4].

Our paper focuses on the social movement of BLM and the social protest cycle around the death of George Floyd. Analyzing a dataset from the charitable crowdfunding platform GoFundMe, we examine how the events surrounding the death of George Floyd and the corresponding media attention have influenced the number of donations for campaigns associated with the interests of the black community in subsequent months. By applying a difference-in-difference (DID) estimation strategy, we find that crowdfunding campaigns related to the black community are positively influenced by the BLM movement and the media attention it received over a period of at least ten months. In addition, we find that this positive effect is highly heterogeneous among campaigns, as campaigns with a societal goal experienced an increase in donations for ten months, whereas campaigns with a personal goal only saw a sharp increase in donations in the three months after George Floyd's death.

There is a growing number of literature that identifies differences among certain recipient groups in crowdfunding e.g., among different genders [5] or minorities [6]. The observed differences emphasize the relevance of our research, as we also deal with heterogeneous effects that a social movement has on different campaigns with different recipients. This paper makes several contributions. First, our findings contribute to the research stream on charitable crowdfunding campaign donation behavior, with our distinction between societal and personal campaigns providing a new perspective on the analysis of charitable crowdfunding. To the best of our knowledge, we are the first to classify fundraising campaigns on crowdfunding platforms into personal and societal campaigns by employing a natural language processing approach. Second, our results make a novel contribution to the study of donation behavior on crowdfunding platforms, showing the difference in the number of donations received by, on the one hand, societal campaigns linked to a social movement and, on the other, personal campaigns, over the course of a social protest cycle. Third, our results provide the first important insights into the long-term effects of social movements and associated social protest cycles on donation behavior on crowdfunding platforms.

\section{Related Literature}

The history of research on donation behavior and success factors of donation campaigns primarily lies in psychology and marketing research [7]. The characteristics of web-enabled charitable crowdfunding platforms differ from traditional fundraising. As many donations on crowdfunding platforms are anonymously, the explanation that people donate due to their concern for the social image is mitigated [8]. Furthermore, reciprocity as a driver of charitable giving is challenged, as many donations are made by people who have little or no social connection to the fundraiser [9].

Previous research observed different dynamics in the donation behavior on charitable crowdfunding platforms. For example, the completion effect posits that a donor makes significantly larger, faster and more frequent donations when the donation leads to the campaign's completion [10]. Donors also tend to use others' prior donation amounts as a benchmark for their own contribution, meaning they align with the donated amounts of previous donations i.e., anchoring effect [11]. Comparing the donation behavior to organizations and to individuals, donations to organizations seem to be primarily influenced by outcome-related factors (i.e., campaign target amounts and the likelihood of meeting the target), while donations to individuals are primarily influenced by interaction-related factors i.e., the interaction between the fundraiser and the donors [12]. The character of the campaign text has also been found to influence the likelihood of donations for a campaign. A campaign with a rational and credible appeal, and a positive message, has a positive effect on donations, compared with one that makes an emotional, and negatively phrased appeal [13]. Our paper adds to this stream of literature by considering the donation behavior in charitable crowdfunding for a social movement accompanied by high (social) media attention.

Social movements usually seek change in relation to specific, usually controversial issues. They consist of individuals who join forces because of their common convictions [14] and collective aim to achieve political, cultural and social change, using different resources [15]. In the process, social movements are followed by media, which in turn brings them to the attention of broader society. They usually extend over a long period of time, characterized by recurring periods of intense unrest and contentious protest activities. These intense periods are called social protest cycles and usually emerge in response to specific events. They take the form of intense protest actions with high levels of participation and rapidly spreading momentum. Social media (e.g., Twitter) as well as traditional media (e.g., television) and their users are increasingly used and 
integrated in social protest cycles. Through the use of hashtags and posts, they have clearly expressed their concerns and have gained high visibility worldwide [2].

Little is known about the donation behavior in social movements. In the literature on prosocial lending, the reporting of major crises increases all types of charitable funding for people who are, directly or indirectly, affected by that crisis. For instance, it has been observed that lenders are more likely to lend to a borrower when she is from a country that has seen a natural disaster [16]. Similarly, the ratio of loans for borrowers from countries involved in the Arab Spring increased exponentially during that period of time, compared to other countries [17]. By investigating crowdfunding campaigns related to the social protest cycle of the BLM movement in 2020, we add another perspective to the literature on the effect of a social movement on charitable crowdfunding.

\section{Theoretical Background and Derivation of Hypotheses}

The BLM movement is an international movement that opposes violence against black people. It officially started in 2013 and consists of a group of people who collectively advocate for the concern of the black community and organize regular protests against racism using a variety of resources, including fundraising [18]. Thus, the BLM movement can be classified as a social movement. This social movement has seen recurring periods of intense waves of protest and social unrest. The latest well-known example is the wave of protests that erupted in mid-2020 around the events of the death of George Floyd, in which thousands of people participated in a variety of ways and which attracted high social media attention worldwide. These intense waves of protest can be referred to as a social protest cycle.

Given the high level of media attention that social movements and social protest cycles receive, as well as the fact that media influence the success of fundraising campaigns [3, 19], it is reasonable to posit that fundraising campaigns whose content aligns with the goals of the BLM movement and those of the social protest cycle connected to the death of George Floyd will benefit from the attention and, hence, help to generate donations. From this, we derive our first hypothesis:

H1: Fundraising campaigns that are thematically aligned with the goals of a social movement, and supported by an active social protest cycle, benefit from the media publicity in the short term, in terms of high numbers of donations.

We are interested in analyzing the donation behavior for campaigns on charitable crowdfunding platforms with different characteristics as a result of a social protest cycle. Consequently, it is important to consider different motivations for donating. The literature on donation behavior makes a basic distinction between donations motivated by impact, where the donor wants to make a positive impact by improving another person's life [20], or by moral concerns, where the donor seeks to maintain a positive moral selfconcept [21, 22]. In the latter case, people 'offer assistance primarily to reaffirm a self-image as a caring, helpful individual' [23].

Based on construal-level theory, we argue that the abstraction levels of personal and societal goals differ fundamentally [24]. The construal level theory describes the connection between psychological distance and mental construal. It assumes that every person is in the here and now and that objects that deviate from this state (e.g., in time, space, social distance, or even hypothetically) are perceived with more mental abstraction. Overcoming the self in the here and now requires mental construal, and the farther removed an object (i.e., the cause of a crowdfunding campaign) is from direct experience, the higher (more abstract) the level of construal of that object [24]. A donation to a campaign pursuing a personal goal is less abstract than to one pursuing a societal goal. Previous research suggests that a morally expansive person tends to show a stronger interest in the needs and welfare of a larger set of social groups than of a narrow set of ingroups $[25,26]$. We argue that campaigns that are focused more on personal goals are more likely to be supported by impact-motivated donors, whereas campaigns with more of a societal concern focus (e.g., racial discrimination, or climate change) are more likely to be supported by altruistic people, who consider such issues as moral issues for which they feel an obligation to do the 'right thing', including to make 'sacrifices' through their donation [27]. Given that social movements and their respective social protest cycle pursue rather abstract, societal issues, we argue that a social protest cycle will particularly stimulate morallyoriented donations from people with a more abstract mindset. Hence, the corresponding abstraction levels regarding the campaign goal (i.e., societal) and a donor's mindset (i.e., moral) have a positive effect on donations. This is supported by research findings from psychology, which state that people with an abstract mindset are more likely to behave according to their abstract value priorities compared to people who have a concrete mindset [28]. This leads to our second hypothesis:

H2: In the long term, fundraising campaigns that pursue a societal goal receive a higher number of donations from a social protest cycle than fundraising campaigns that pursue a personal goal. 


\section{Empirical Analysis}

In order to empirically test our hypothesis, we examine the effect of the BLM movement after the death of George Floyd on donation behavior for different charitable crowdfunding projects.

\subsection{Data}

We used a customized web-crawler to collect donation campaigns that were listed over the period from December 2019 to February 2021 on GoFundMe.com. GoFundMe is one of the largest donation-based crowdfunding platforms which has helped to raise more than $\$ 9$ billion through more than 120 million individual donations since its launch in 2010 [1]. Our dataset contains information about monthly donations for all campaigns that are based in one of the four largest US metropolitan areas, i.e., New York City, Los Angeles, Chicago, Dallas, and in the largest Canadian metropolitan area, i.e., Toronto. For each campaign, we collect the month the campaign was launched (MONTH_LAUNCHED), dummies for the assigned category (e.g., Animals \& Pets, Kids \& Family, dummies for the location of the fundraiser, the funding goal (FUNDING_GOAL), the fund description where fundraisers narratively describe the campaign's cause, and the text length of the fund description (DESCR_LENGTH). On a monthly level, we additionally obtain information about the donations made for each campaign, including the number of donations (NUM_DONATIONS, our dependent variable), the donation amount (DON_AMOUNT), a percentage score indicating how much of the funding goal has already been raised (\%_GOAL_REACHED), the share of donors that have their identity verified on the platform (SHARE_VERIFIED), the share of anonymous donations (SHARE_ANONYMOUS), and a percentage score indicating how many donations were submitted offline (SHARE_OFFLINE). We also retrieve information about the number of comments donors have posted for each campaign in each month (NUM_COMMENTS), and the number of updates each fundraiser has published per month (NUM_UPDATES).

To identify whether a campaign is associated with the interests of the black community, we create a dummy variable $B L A C K$ by using a dictionary approach (referred to as D). More specifically, BLACK is set to 1 if the fund description of a campaign contains words pertaining to the interests of black people (e.g., "black live", "black communities", or "people of color"). Our self-created dictionary comprises 53 terms and is based upon several websites referring to the BLM movement (e.g., https://blacklivesmatter.com/). According to this measure, 1,842 campaigns in our dataset are associated with the interests of the black community. To validate our dictionary approach, we draw a random subsample of 400 campaigns from our dataset, consisting of 100 campaigns labelled as associated with the interests of the black community (i.e., $B L A C K=1$ ) and 300 that are labelled as $B L A C K=0$. We then asked four research assistants to read the corresponding fund descriptions of the campaigns and label them as either associated with the interests of the black community, or not. Each of the assistants independently labelled 200 campaigns and, to reduce biases stemming from one coder, we gave the same campaign to two assistants. Note that the label of our dictionary approach was not visible for them during the coding process. We then calculated the interrater reliability for each subsample with the labels derived from our dictionary. For the first 200 campaigns (Sample 1), we find an agreement of $93 \%$ between the two coders and the dictionary approach. The remaining 200 campaigns (Sample 2) resulted in an interrater agreement of $91 \%$ between the research assistants and our dictionary. The corresponding values of 0.92 for Cohen's Kappa on sample 1 (0.87 on sample 2$)$ and 0.92 for Krippendorff's Alpha on sample 1 (0.88 on sample 2) also indicate substantial agreement between the coders and the dictionary [29]. Hence, we conclude that our dictionary approach effectively identifies campaigns that are associated with the interests of the black community.

Table 1 reports summary statistics which represent the monthly averages of our panel dataset. One can see that the campaigns posted on the website are highly diverse in terms of their funding goal, which is reflected in the high standard deviation. Campaigns on GoFundMe follow the Keep-It-All model, which means that donations are not refunded to donors in case a campaign does not reach its campaign goal. Moreover, campaigns are not restricted to deadlines or time limits and hence, donors can continue to contribute to a campaign that has already reached its goal [1]. That is why some fundraisers tend to set a comparably low funding goal, such that an average campaign on GoFundMe raises about 19 times more than their actual funding goal. Moreover, as the campaigns posted on the crowdfunding platform span a wide range of topics and funding goals, the number of donations is highly diverse, as is the donation amount for each campaign. In total, our panel dataset comprises 69,394 campaigns and $2,902,258$ individual donations. 
Table 1: Summary Statistics

\begin{tabular}{|l|l|l|}
\hline & Mean & Std. Dev. \\
\hline FUNDING_GOAL & 75,142 & $4,173,821$ \\
\hline DESCR_LENGTH & 259 & 259 \\
\hline NUM_DONATIONS & 20 & 52 \\
\hline DON_AMOUNT & 1,742 & 15,042 \\
\hline \%_GOAL_REACHED & 19 & 908 \\
\hline SHARE_VERIFIED & 0.78 & 0.38 \\
\hline SHARE_ANONYMOUS & 0.26 & 0.29 \\
\hline SHARE_OFFLINE & 0.03 & 0.16 \\
\hline NUM_COMMENTS & 1.15 & 6.07 \\
\hline NUM_UPDATES & 0.24 & 0.80 \\
\hline BLACK & 0.03 & 0.17 \\
\hline
\end{tabular}

\subsection{Distinguishing between Campaigns with a Personal and a Societal Concern}

In order to examine the heterogeneous impact of spikes in media attention on crowdfunding campaigns that are associated with a social movement, we need to effectively classify the underlying concern of each campaign. We assume that the concern of each charitable crowdfunding campaign can be categorized as either personal or societal. In line with prior literature, we define a campaign's cause as personal if a private matter is paramount in the appeal for donations [30]. This is the case whenever the fundraiser's benefit from donations exceeds the benefit for society. For example, campaigns launched for a personal concern raise funds for the wellbeing of family members, for physical health, for retirement, for education or for serious accidents [30]. In contrast, prior literature defines a campaign's cause to be societal if donations are raised to address a societal problem, e.g., for the prevention of crime and violence, for research on curing diseases, on uncovering the corruption of politicians, or for climate change [30].

Naturally, a key challenge of our study is to effectively identify those campaigns that are associated with personal or societal concerns. We approach this distinction by developing a natural language processingbased machine learning algorithm. The basic idea of our approach is that we use the textual information provided by each fundraiser in the campaign's description to classify the campaigns. Usually, the fund description incorporates detailed information about what the fundraiser intends to spend the raised money on and thus enables unique insights into a campaign's primary cause. Our classification method consists of the following two steps: (1) collecting labelled data for training, and (2) train the machine learning algorithm to classify the remaining campaigns which have not yet been labelled.

\subsubsection{Labelling the Training Data}

In the first step, we used the previously drawn random subsample consisting of 400 campaigns as a training set for our algorithm. Once again, we asked four research assistants to carefully read and label the fund descriptions with respect to the campaign's underlying cause. Each campaign is labelled on a 3-point scale, where 1 represents a "societal concern", 2 refers to a "personal concern" and 3 is used for campaigns where the coders are not sure which label fits best. We instructed the assistants together during an in-person coaching session, explaining the previously provided definitions of personal and societal concerns, and providing five pre-coded campaigns as examples. Each campaign was processed independently by two assistants, meaning that each assistant labelled 200 campaigns in total. After the coding task, we eliminated all campaigns where the coders completely disagreed upon labelling (i.e., one coder labels a campaign's cause as societal whereas the other coder picked personal as a label). Moreover, we excluded all campaigns where both coders were unsure about the correct classification. As a result, the training set for our algorithm consists of 334 campaigns whose corresponding causes can be clearly identified as either personal or societal.

\subsubsection{Training and Classification}

In step two, we pre-processed each fund description of our dataset by applying stemming, lemmatizing, tokenization, stop word removal, and elimination of non-alphabetical characters [31]. Afterwards, we vectorized the pre-processed texts using scikit-learn's TFIDF Vectorizer, resulting in a transformation where each fund description is represented as a vector of words. We then supplement our vector with a standardized variable indicating the text's length. We tried out several classification algorithms for the labelling task, including Naïve Bayes, Random Forest, Support Vector Machine (SVM), and K-Nearest Neighbors (KNN). For each algorithm, we additionally applied Grid Search to optimize the choice of hyperparameters. The training set was split into two parts, such that $80 \%$ were used to train the classifier and the remaining $20 \%$ served as our validation set. Assessing the performance of the algorithms in terms of accuracy and F1-score on the validation set, we conclude that the SVM algorithm outperforms the other algorithms. With an accuracy of $86.57 \%$ and F1 scores of 0.91 for the identification of personal concern $(0.73$ for the identification of societal concerns), the algorithm yields the best performance on the validation set. Thus, we proceed with our classification procedure by applying the SVM algorithm to our whole dataset. As a result, the 
algorithm predicts two probabilities for each campaign: (1) a probability for the "personal concern"-label and (2) a probability for the "societal concern"-label. Note that the sum of (1) and (2) is equal to $100 \%$. For example, if a campaign is associated with a probability of $60 \%$ of raising funds for a personal concern, then the probability that it raises funds for a societal concern equals $40 \%$. To rule out labelling decisions that are based on probability values close to the threshold of $50 \%$ (e.g., $51 \%$ vs. $49 \%$ ), we only label campaigns with a probability of $60 \%$ or more for either the "personal concern"-label or the "societal concern"-label [32]. Our classification procedure results in two binary variables, namely PERSONAL and SOCIET AL. In that sense, PERSONAL is set to 1 if the computed probability of the SVM algorithm for the "personal concern"-label is $60 \%$ or higher, whereas SOCIETAL equals 1 if the probability for the "societal concern"-label reaches values of $60 \%$ or higher. In total, our classification algorithm identifies $58,374(84.12 \%)$ campaigns to be raised for a personal concern, $7,585(10.93 \%)$ campaigns on a societal concern and 3,434 (4.95\%) which are not labelled.

\subsection{Empirical Model}

To empirically test our hypothesis, we estimate a DID design with multiple interactions between the treatment variable $B L A C K$ and monthly time dummies (see equation (1)).

$$
\begin{aligned}
& \ln \left(\text { NUM_DONATIONS }_{i t}\right)=\beta_{0}+\sum_{j=1}^{T} \alpha_{j} \cdot \text { MONTH }_{i t j} * \\
& \text { BLACK }_{i}+\beta_{1} \cdot \text { BLACK }_{i}+\sum_{j=1}^{T} \theta_{j} \cdot \text { MONTH }_{i t j}+\beta_{2} \gamma_{i t}+ \\
& \delta_{i}+\varepsilon_{i t}
\end{aligned}
$$

In a DID model, the effect of a certain event on a dependent variable is measured by comparing a treated group, which was confronted with an event, with a comparable control group, which was not affected by that event, before and after this event happened. Here, the dependent variable $\ln \left(N_{U} M_{-} D O N A T I O N S_{i t}\right)$ represents the natural logarithm of the number of donations of campaign $i$ in month $t$. The death of George Floyd on $25^{\text {th }}$ May 2020 represents an exogeneous event for campaigns associated with the interests of black people, as it triggered huge media attention in the following weeks on the topic of racial discrimination (see Figure 1). Therefore, the variable $B L A C K$ serves as our treatment variable, resulting in a control group which consists of all campaigns related to other topics (i.e., $B L A C K=0$ ). We assess the suitability of our control group in our empirical analysis as well as in our robustness checks, where we also examine the role of the COVID-19 pandemic in our research setting. The average treatment effect on the treated (ATT) campaigns is captured in the interaction terms of
MONTH $H_{i t j} * B L A C K_{i}$ after the treatment $\left(M O N T H_{i t j} \geq\right.$ May 2020). To build up a reference point for the interpretation of the treatment effect, our model leaves out the last month and its respective interaction term before the treatment takes place (April 2020). Thus, the interaction terms estimate the average differences in donations for campaigns associated with the black community and campaigns not associated with the black community after the death of George Floyd. We also incorporate the variables of the interaction separately in our specification, where $M O N T H_{i t j}$ represents a single month $j$ that equals 1 if $t$ equals $j$. Moreover, $\gamma_{i t}$ is a vector of time-varying control variables consisting of the number of months since the campaign has been launched, the current donation amount in month $t$, a percentage score of having reached the goal amount in month $t$, the proportion of verified-, anonymous-, and offline donors, the number of updates, and the number of comments. Finally, $\delta_{i}$ represents campaign fixed effects and $\varepsilon_{i t}$ is a random error term. In order to examine the heterogeneous impact of George Floyd's death and its corresponding media attention on campaigns raised for different concerns, we estimated equation (1) separately for campaigns with a personal concern (i.e., $P E R S O N A L=1$ ) and for campaigns with a societal concern $($ SOCIET AL $=1)$

As depicted in Figure 1, the public interest on news about the BLM movement peaks in the first month after George Floyd's death, which is associated with a high media coverage in terms of global news reporting [33], social media attention [34], and local protests [35] directly after the event. In the following three months the media attention quickly declines to a moderate level that ranges between $10 \%$ and $30 \%$ of the interest observable in June 2020. In the subsequent months, the search trend for the BLM movement almost disappears, suggesting low media coverage $[34,35]$.

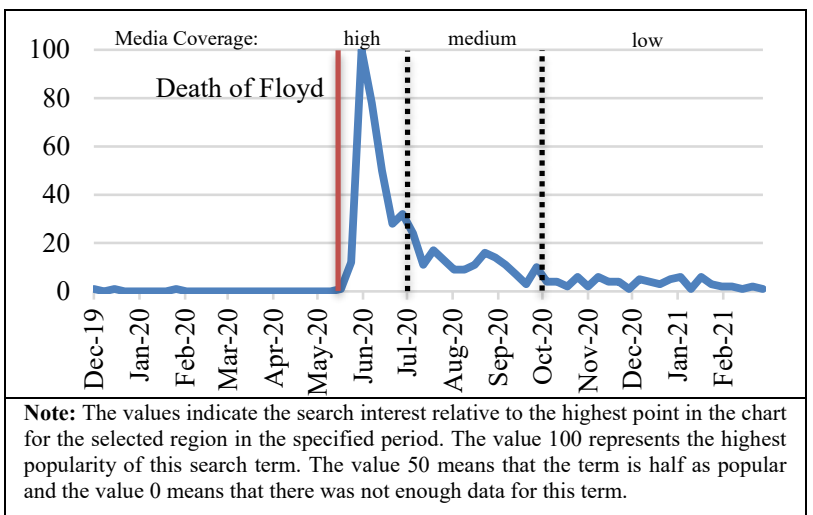

Figure 1: Popularity of the Search Term "Black Lives Matter" on Google News Worldwide 


\subsection{Results}

Table 2 presents our empirical results when estimating equation (1) for all campaigns (Model 1), only for campaigns with a societal concern (Model 2) and only for campaigns with a personal concern (Model $3)$. First, we find insignificant coefficients in the pretreatment period (December 2019-March 2020) for all three models, which indicates that the donation behavior for campaigns related to the black community and campaigns related to other topics was quite similar before the treatment took place. Hence, we find support for the common trends assumption [36]. With respect to Model 1, we find a massive increase in the number of donations for campaigns associated with the black community after George Floyd's death on $25^{\text {th }}$ May 2020. In June 2020, a month with high media coverage for the BLM movement, the number of donations for the black community was $164 \%$ higher than those submitted in April 2020 (our reference month). Afterwards, in the months with medium and low media coverage (July 2020 - February 2021), the coefficients of the interaction terms for the number of donors and the donation amount stay positive and statistically significant up till the end of our observation period (February 2021). Hence, our results indicate that George Floyd's death and the associated peak in the media attention in June 2020 positively affects donations for crowdfunding campaigns for at least ten months. We thus find support for Hypothesis 1. In addition, we can even observe a long-term increase in the number of donations for campaigns associated with a social movement after a social protest cycle has increased the attention given to it in the media.

In Model (2) we estimate equation (1) only for campaigns that raise funds for a societal concern (i.e., SOCIETAL = 1). Here, we also find a significant increase of $182.3 \%$ in the number of donations for campaigns related to the black community in the month with high media coverage (June 2020), compared to the number of donations submitted during April 2020. Thereafter, the interaction terms in the months July 2020 - October 2020 remain positive statistically significant on a $5 \%$ level. This means that, even in times of medium and low media coverage for the BLM movement, the number of donations for campaigns associated with the black community is higher compared to the donations made in April 2020. In January 2021 and up until February 2021, we again observe a significant increase in the number of donations.
Table 2: Regression Results

\begin{tabular}{|c|c|c|c|}
\hline Model & (1) & (2) & (3) \\
\hline & $\begin{array}{c}\text { All } \\
\text { campaigns }\end{array}$ & $\begin{array}{c}\text { Societal } \\
\text { campaigns }\end{array}$ & $\begin{array}{c}\text { Personal } \\
\text { campaigns }\end{array}$ \\
\hline Variables & $\begin{array}{l}\ln \left(N_{U M}\right. \\
\text { DONATION }\end{array}$ & $\begin{array}{l}\ln \left(N_{U M}\right. \\
\text { DONATION }\end{array}$ & $\begin{array}{l}\ln \left(N_{U} M_{-}\right. \\
\text {DONATION }\end{array}$ \\
\hline$D E C \_19 * B L A C K$ & $\begin{array}{l}-0.203 \\
(0.276)\end{array}$ & $\begin{array}{l}-0.257 \\
(0.517)\end{array}$ & $\begin{array}{l}-0.081 \\
(0.330)\end{array}$ \\
\hline$J A N \_20 * B L A C K$ & $\begin{array}{c}0.027 \\
(0.265)\end{array}$ & $\begin{array}{l}0.495 \\
(0.468)\end{array}$ & $\begin{array}{c}0.002 \\
(0.337) \\
\end{array}$ \\
\hline$F E B \_20 * B L A C K$ & $\begin{array}{c}0.052 \\
(0.268)\end{array}$ & $\begin{array}{c}0.227 \\
(0.482)\end{array}$ & $\begin{array}{c}0.177 \\
(0.341)\end{array}$ \\
\hline$M A R \_20 * B L A C K$ & $\begin{array}{l}-0.206 \\
(0.246)\end{array}$ & $\begin{array}{l}-0.131 \\
(0.449) \\
\end{array}$ & $\begin{array}{c}0.020 \\
(0.292)\end{array}$ \\
\hline$A P R \_20 * B L A C K$ & \multicolumn{3}{|c|}{ Omitted } \\
\hline $\begin{array}{c}M A Y \_20 * B L A C K \\
\text { (Death of Floyd) }\end{array}$ & $\begin{array}{c}0.688 * * * \\
(0.230)\end{array}$ & $\begin{array}{l}0.684 * * \\
(0.343) \\
\end{array}$ & $\begin{array}{l}0.733^{* *} \\
(0.355) \\
\end{array}$ \\
\hline $\begin{array}{r}U N \_20 * B L A C K \\
\text { (high media coverage) }\end{array}$ & $\begin{array}{c}1.640^{* * *} \\
(0.217)\end{array}$ & $\begin{array}{c}1.823 * * * \\
(0.324)\end{array}$ & $\begin{array}{c}1.356^{* * *} \\
(0.318)\end{array}$ \\
\hline $\begin{array}{l}\text { JUL_20 * BLACK } \\
\text { (mod.media coverage) }\end{array}$ & $\begin{array}{c}1.043 * * * \\
(0.218)\end{array}$ & $\begin{array}{c}1.324 * * * \\
(0.323)\end{array}$ & $\begin{array}{l}0.680^{* *} \\
(0.329) \\
\end{array}$ \\
\hline $\begin{array}{c}\text { AUG_20 * BLACK } \\
\text { (mod. media coverage) }\end{array}$ & $\begin{array}{c}0.762 * * * \\
(0.217)\end{array}$ & $\begin{array}{l}0.810^{* *} \\
(0.326)\end{array}$ & $\begin{array}{l}0.605^{*} \\
(0.328)\end{array}$ \\
\hline $\begin{array}{l}S E P \_20 * B L A C K \\
\text { (mod. media coverage) }\end{array}$ & $\begin{array}{c}0.649 * * * \\
(0.222)\end{array}$ & $\begin{array}{l}0.774 * * \\
(0.335)\end{array}$ & $\begin{array}{c}0.402 \\
(0.333)\end{array}$ \\
\hline $\begin{array}{c}\text { OCT_20 * BLACK } \\
\text { (low media coverage) }\end{array}$ & $\begin{array}{c}0.695 * * * \\
(0.227) \\
\end{array}$ & $\begin{array}{l}0.726^{* *} \\
(0.341) \\
\end{array}$ & $\begin{array}{c}0.488 \\
(0.336) \\
\end{array}$ \\
\hline $\begin{array}{c}\text { NOV_20 } * B L A C K \\
\text { (low media coverage) }\end{array}$ & $\begin{array}{l}0.526^{* *} \\
(0.225)\end{array}$ & $\begin{array}{c}0.502 \\
(0.338)\end{array}$ & $\begin{array}{c}0.130 \\
(0.336)\end{array}$ \\
\hline $\begin{array}{c}D E C \_20 * B L A C K \\
\text { (low media coverage) }\end{array}$ & $\begin{array}{c}0.795 * * * \\
(0.227) \\
\end{array}$ & $\begin{array}{l}0.619^{*} \\
(0.339) \\
\end{array}$ & $\begin{array}{c}0.459 \\
(0.343) \\
\end{array}$ \\
\hline $\begin{array}{c}J A N \_21 * B L A C K \\
\text { (low media coverage) }\end{array}$ & $\begin{array}{c}1.051 * * * \\
(0.230)\end{array}$ & $\begin{array}{l}0.773^{* *} \\
(0.345)\end{array}$ & $\begin{array}{l}0.714^{* *} \\
(0.344)\end{array}$ \\
\hline $\begin{array}{c}F E B \_21 * B L A C K \\
\text { (low media coverage) }\end{array}$ & $\begin{array}{c}0.711 * * * \\
(0.248)\end{array}$ & $\begin{array}{l}0.891^{* *} \\
(0.372) \\
\end{array}$ & $\begin{array}{c}0.265 \\
(0.377) \\
\end{array}$ \\
\hline Monthly FE & $\checkmark$ & $\checkmark$ & $\checkmark$ \\
\hline Campaign FE & $\checkmark$ & $\checkmark$ & $\checkmark$ \\
\hline $\begin{array}{l}\text { Campaign } \\
\text { Controls }\end{array}$ & $\checkmark$ & $\checkmark$ & $\checkmark$ \\
\hline$N$ & 144,559 & 16,628 & 120,573 \\
\hline$R^{2}$ & 0.701 & 0.677 & 0.708 \\
\hline
\end{tabular}

Model (3), by contrast, shows the results of our regression only for campaigns related to a personal concern (i.e., $P E R S O N A L=1$ ). The estimates reveal an increase in the number of donations for campaigns related to the black community of $135.6 \%$ in June 2020 , the month with high media coverage. However, as the mostly insignificant interaction terms for the following months after July 2020 indicate, the number of donations quickly fall back to nearly the same level as before the treatment in the months with medium or low media coverage. Only in January 2021, is an increase in the number of donations once again observable. However, given that campaigns associated with a societal concern experience an increase in the number 
of donations that is mostly higher in size and lasts for at least four months longer (August 2020-October 2020 as well as February 2021) in comparison to campaigns for a personal cause, we also find support for Hypothesis 2.

\subsection{Robustness Checks}

One might be concerned that our results could be biased due to the fact that following the death of George Floyd, a large number of campaigns related to the black community were launched. Although we control for the number of months since a campaign was launched, we re-run our regression and restrict our dataset to campaigns launched before the treatment took place. For this subset, our results remain qualitatively unchanged, indicating that higher donations for newly launched campaigns after the treatment do not bias our results.

Moreover, we re-ran our regression with alternative thresholds for our identification of personal and societal campaigns. Instead of a probability threshold of $60 \%$ used to identify the campaign's causes, we now employ thresholds of $70 \%$ and $80 \%$, respectively. Again, this did not qualitatively change our results.

Lastly, one might be concerned that our results could be biased due to the COVID-19 pandemic having reached the U.S. in March 2020 and thus strongly affecting people's donation behavior. Indeed, our data shows that about 15,091 of the campaigns mention words like "Covid" or "Corona" in their fund descriptions. However, our DID specification is designed to rule out COVID-related changes in donation behavior as long as the treatment and the control group follow the same trends. Based on the insignificant interaction terms between March 2020 and our treatment variable, we obtain a first indication that the donation behavior for campaigns related to the black community and for campaigns related to other topics are comparable (see Table 2). However, to rule out that campaigns related to the black community receive more funding because they are much more affected by the COVID-19 pandemic in the following months, we rerun our regression and exclude all campaigns mentioning the coronavirus in their fund description. For all types of campaigns, the results remain qualitatively unchanged. However, for societal campaigns, some of the interaction terms for the months between August 2020 to February 2021 become insignificant. By contrast, for personal campaigns, only the coefficients for the interaction terms in June 2020 and January 2021 reveal significant differences. Although some of our results may thus also be attributable to the COVID-19 pandemic, the general trend of societal campaigns being affected more strongly and longer by the BLM movement than personal campaigns is observable here, too.

\section{Discussion}

In recent years, the trend to raise money for social movements, natural catastrophes and other important social events on charitable crowdfunding platforms has risen considerably [16, 17]. Such events are often accompanied by an enormous, yet temporary, peak in media coverage and thus raise awareness of societal issues among citizens [2]. Our analysis provides a starting point on how such media exposure for a particular event affects donation behavior for different types of charitable crowdfunding campaigns. It may come as little surprise, then, that our results display a strong, short-term increase in donations in support of the black community after the death of George Floyd. Fundraising campaigns that are thematically aligned with the goals of a social movement and an active social protest cycle can hence benefit from the social protest cycle of a social movement. However, our results also suggest that the increase in donations following a social protest cycle is highly heterogeneous among different types of campaigns. We provide evidence that campaigns supporting a societal concern benefit longer and to a larger extent from the short-term media coverage than campaigns supporting a personal concern. For societal campaigns, the moment seems to have become a movement, as a consistent, long-term increase in donations can be observed compared to the trend preceding George Floyd's death. In comparison, the support for personal campaigns falls back to the presocial protest cycle level within three months. Based on construal-level theory, we argue that this difference arises because social movements such as BLM particularly appeal to people with a more pronounced moral mindset, or they make people more aware of their moral obligation to support such matters. Therefore, people may donate more to campaigns connected to the social movement which display an abstract, societal goal in their fund description. Considering our results as part of a bigger picture, we argue that the diversity of donors, fundraisers and campaigns induces further analysis for different subgroups to examine the heterogeneous effects occurring in donation-based crowdfunding platforms (e.g., campaigns supporting a matter of the black community or campaigns supporting a personal or societal matter). We hope that our research provides an impetus for further research on heterogenous effects in donation-based crowdfunding for relevant and specific groups of campaigns, donors or fundraisers. Such analyses can and should also aim to uncover possible hidden discrimination and inequalities and thus actively counteract them. 


\section{Conclusion}

Our results open up important insights into donation behavior on crowdfunding platforms for platform providers, campaign operators and donors. From a practical perspective, our research implies that providers of charitable crowdfunding platforms need to be aware of the heterogeneous donation behavior that arises if a social movement gains media attention. This implies that as platform providers currently highlight popular and big fundraising campaigns which are often associated with a societal goal on their platform [1], they may think about highlighting campaigns with a personal concern to be related to a social movement on their website, such that fundraisers that follow a personal goal connected to the movement can also benefit longer from an increased donation level. This is especially relevant for donation platforms such as GoFundMe, as their initial goal is to enable private individuals to make donation appeals for private causes [37]. A second practical implication of our research is, that our results serve as a guide for campaign operators to better assess donor behavior after social movements are trending on social media. Especially when fundraisers aim to collect money for personal concerns that are associated with that movement, it is crucial to directly launch the crowdfunding campaign after the concern has gained attention in media.

Our analysis is subject to limitations, which at the same time offer great opportunities for future research. We plan to further enhance our paper by taking the following steps. First, we only examined the effect of the BLM movement and its respective media attention on the number of donations on crowdfunding campaigns. An analysis of other social movements (e.g., the \#MeToo movement) could reveal additional insights

\section{References}

[1] GoFundMe, "About GoFundMe". www.gofundme.com/c/about-us, accessed 4-16-2021.

[2] M. Tarafdar and D. Kajal Ray, "Role of Social Media in Social Protest Cycles: A Sociomaterial Examination", Information Systems Research, 2021.

[3] S.E. Morgan, T.R. Harrison, S.D. Long, W.A. Afifi, M.T. Stephenson, M.S. Stephenson, and T. Reichert, "Family Discussions about Organ Donation: How the Media Influences Opinions about Donation Decisions", Clinical Transplantation, 19(5), 2005, pp. 674-682.

[4] K. Bellings, "George Floyd Update: GoFundMe Pages Raise Nearly \$15 Million To Support Floyd's Family", accessed 4-30-2021. about donation behavior in crowdfunding markets after such movements have gained media attention. In that sense, it would also be interesting to not only investigate the impact on the number of donations, but also on the donation amount for campaigns related to the movement. Second, we do not conduct a validation for our natural language processing-based approach to distinguish between personal and societal campaigns. Although we provide evidence that the algorithm performs quite well on a pre-coded validation set and carefully designed our labelling process as we do not label campaigns for which our machine learning algorithm predicts similar probabilities for both personal and societal concerns, we have not assessed the classification performance on the remaining dataset so far. Hence, we plan to conduct another manual coding on a random subsample of classified campaigns to validate the algorithm's results. Third, our conclusion of the results is so far only based on the suggestions made by construal-level theory which suggests that donors perceive social movement goals as something moral and abstract. Therefore, to strengthen the link between this theory and our theoretical explanation of our results, we plan to examine if social movements are perceived by potential donors as something moral and abstract. As our analysis relies on observational data, it might add value to conduct a survey among crowdfunding donors and verify if moral-oriented people prefer to donate to a societal cause, while impact-oriented people prefer to donate to a personal cause. To complement this, it would be useful to examine the comments left by donors on a fundraising campaign to which they have donated. Their comments could even be used to determine whether they are consciously supporting privately or socially oriented fundraising causes. ${ }^{1}$

[5] S. Bapna and M. Ganco, "Gender gaps in equity crowdfunding: Evidence from a randomized field experiment", Management Science, 67(5), 2021, pp. 2679-2710.

[6] P. Younkin and V. Kuppuswamy, "The colorblind crowd? Founder race and performance in crowdfunding", Management Science, 64(7), 2018, pp. 3269-3287.

[7] J.M. Weyant and S.L. Smith, "Getting More by Asking for Less: The Effects of Request Size on Donations of Charity", Journal of Applied Social Psychology, 17(4), 1987, pp. 392-400.

[8] D. Ariely, A. Bracha, and S. Meier, "Doing good or doing well? Image motivation and monetary incentives in behaving prosocially", American Economic Review, 99(1), 2009, pp. 544-555.

[9] C.M. Fong, "Evidence From an Experiment on Charity to Welfare Recipients: Reciprocity, Altruism and the

\footnotetext{
${ }^{1}$ This work was partially supported by the German Research Foundation (DFG) within the Collaborative Research Centre On-The-Fly Computing (GZ: SFB 901/3) under the project number 160364472.
} 
Empathic Responsiveness Hypothesis", The Economic Journal, 117(522), 2007, pp. 1008-1024.

[10] N. Argo, D. Klinowski, T. Krishnamurti, and S. Smith, "The completion effect in charitable crowdfunding", Journal of Economic Behavior \& Organization, 172, 2020, pp. 17-32.

[11] G. Burtch, A. Ghose, and S. Wattal, "An Empirical Examination of Users' Information Hiding in a Crowdfunding Context", 34th International Conference on Information Systems, Milan, Italy. 2013.

[12] R. Gleasure and J. Feller, "Does Heart or Head Rule Donor Behaviors in Charitable Crowdfunding Markets?", International Journal of Electronic Commerce, 20(4), 2016, pp. 499-524.

[13] A. Majumdar and I. Bose, "My Words for Your Pizza: An Analysis of Persuasive Narratives in Online Crowdfunding", Information \& Management, 55(6), 2018, pp. 781-794.

[14] M. Diani, "The concept of social movement", The sociological review, 40(1), 1992, pp. 1-25.

[15] N.Z. Mayer, R.H. Bates, E. Comisso, P. Lange, J. Migdal, and H. Milner, Comparative Perspectives on Social Movements: Political Opportunities, Mobilizing Structures, and Cultural Framings, Cambridge University Press, 1996.

[16] G. Burtch, A. Ghose, and S. Wattal, "Cultural Differences and Geography as Determinants of Online Prosocial Lending", MIS Quarterly, 38(3), 2014, pp. 773-794.

[17] A. Sabzehzar, Y. Hong, and R. Santanam, "People Don't Change, Their Priorities Do: Evidence of Value Homophily for Disaster Relief", 41st International Conference on Information Systems, Virtual Conference. 2020.

[18] Black Lives Matter, "About". www.blacklivesmatter.com/about/, accessed 0806.2021 .

[19] M.Y. Rady, J.L. McGregor, and J.L. Verheijde, "Mass Media Campaigns and Organ Donation: Managing Conflicting Messages and Interests", Medicine, Health Care and Philosophy, 15(2), 2012, pp. 229-241.

[20] M. Touré-Tillery and A. Fishbach, "Too far to help: The effect of perceived distance on the expected impact and likelihood of charitable action", Journal of personality and social psychology, 112(6), 2017, pp. 860-876.

[21] C.D. Batson and A.A. Powell, "Altruism and prosocial behavior", Handbook of psychology, 2003, pp. 463484.

[22] A.J. Xu, M.A. Rodas, and C.J. Torelli, "Generosity without borders: The interactive effect of spatial distance and donation goals on charitable giving", Organizational Behavior and Human Decision Processes, 161, 2020, pp. 65-78.

[23] J.F. Dovidio, "Helping Behavior and Altruism: An Empirical and Conceptual Overview", in Advances in Experimental Social Psychology Volume 17. 1984. Elsevier.
[24] Y. Trope and N. Liberman, "Construal-level theory of psychological distance", Psychological review, 117(2), 2010 , p. 440.

[25] D. Crimston, P.G. Bain, M.J. Hornsey, and B. Bastian, "Moral expansiveness: Examining variability in the extension of the moral world", Journal of personality and social psychology, 111(4), 2016, pp. 636-653.

[26] A. Reed II and K.F. Aquino, "Moral identity and the expanding circle of moral regard toward out-groups", Journal of personality and social psychology, 84(6), 2003, p. 1270.

[27] I. Knez, "Is Climate Change a Moral Issue? Effects of Egoism and Altruism on Pro-Environmental Behavior", Current Urban Studies, 04(02), 2016, pp. 157-174.

[28] C.J. Torelli and A.M. Kaikati, "Values as predictors of judgments and behaviors: The role of abstract and concrete mindsets", Journal of personality and social psychology, 96(1), 2009, p. 231.

[29] S.E. Stemler, "A comparison of consensus, consistency, and measurement approaches to estimating interrater reliability", Practical Assessment, Research, and Evaluation, 9(1), 2004, p. 4.

[30] M. Randle, R. Eckersley, and L. Miller, "Societal and personal concerns, their associations with stress, and the implications for progress and the future", Futures, 93, 2017, pp. 68-79.

[31] S. Debortoli, O. Müller, I. Junglas, and J. vom Brocke, "Text mining for information systems researchers: An annotated topic modeling tutorial", Communications of the Association for Information Systems, 39(1), 2016, p. 7.

[32] M. Müller, J. Neumann, D. Gutt, and D. Kundisch, "Toss a Coin to your Host-How Guests End up Paying for the Cost of Regulatory Policies", 41st International Conference on Information Systems, Virtual Conference. 2020.

[33] M. Tesler, "Support For Black Lives Matter Surged During Protests, But Is Waning Among White Americans". https://fivethirtyeight.com/features/support-for-blacklives-matter-surged-during-protests-but-is-waningamong-white-americans/.

[34] M. Anderson, M. Barthel, A. Perrin, and E. Vogels, "\#BlackLivesMatter surges on Twitter after George Floyd's death". www.pewresearch.org/facttank/2020/06/10/blacklivesmatter-surges-on-twitterafter-george-floyds-death/, accessed 6-11-2021.

[35] L. Buchanan, Q. Bui, and J.K. Patel, "Black Lives Matter May Be the Largest Movement in U.S. History". www.nytimes.com/interactive/2020/07/03/us/georgefloyd-protests-crowd-size.html, accessed 6-11-2021.

[36] D.H. Autor, "Outsourcing at Will: The Contribution of Unjust Dismissal Doctrine to the Growth of Employment Outsourcing", Journal of Labor Economics, 21(1), 2003, pp. 1-42.

[37] GoFundMe, "How Can I Support Black Lives Matter on GoFundMe?".https://support.gofundme.com/hc/enus/articles/360044485952-How-Can-I-Support-BlackLives-Matter-on-GoFundMe-, accessed 4-23-2021. 